\title{
ON SPECTRA OF COMPOSITION OPERATORS
}

\author{
VALENTIN MATACHE
}

Abstract. In this paper we consider composition operators $C_{\varphi}$ on the Hilbert Hardy space over the unit disc, induced by analytic selfmaps $\varphi$. We use the fact that the operator $C_{\varphi}^{*} C_{\varphi}$ is asymptotically Toeplitz to obtain information on the essential spectrum and spectrum of $C_{\varphi}$, which we are able to describe in select cases (including the case of some hypercyclic composition operators or that of composition operators with the property that the asymptotic symbol of $C_{\varphi}^{*} C_{\varphi}$ is constant a.e.). One of our tools is the Nikodym derivative of the pull-back measure induced by $\varphi$. An alternative formula for the essential norm of a composition operator (valid in select cases), in terms of the aforementioned Nikodym derivative, is established. Estimates of the spectra of adjoints of composition operators are obtained. Based on them, we describe the spectrum of composition operators induced by maps fixing a point, whose iterates exhibit a strong form of attractiveness to that point.

Mathematics subject classification (2010): 47B33, 30D05.

Keywords and phrases: Composition operator, spectrum.

\section{REFERENCES}

[1] C. Bishop, Orthogonal functions in $H^{\infty}$, Pacific J. Math. 220, 1 (2005), 1-31.

[2] P. S. Bourdon, Spectra of some composition operators and some associated weighted composition operators, J. Operator Theory 67, 2 (2012), 537-560.

[3] P. S. Bourdon, D. LeVi, S. K. NARAYAn, And J. H. Shapiro, Which linear-fractional composition operators are essentially normal?, J. Math. Anal. App. 280 (2003), 30-53.

[4] P. S. BOURDON AND B. D. MACCluer, Selfcommutators of automorphic composition operators, Complex Var. Elliptic Equ. 52, 1 (2007), 85-104.

[5] P. S. Bourdon, V. Matache, and J. H. Shapiro, On convergence to the Denjoy-Wolff point, Illinois J. Math. 49, 2 (2005), 405-430.

[6] P. S. BOURDON AND J. H. SHAPIRO, Cyclic composition operators on $H^{2}$, Operator theory: operator algebras and applications, Part 2 (Durham, NH, 1988), 43-53, Proc. Sympos. Pure Math., 51, Part 2, Amer. Math. Soc., Providence, RI, 1990.

[7] P. S. Bourdon And J. H. Shapiro, Cyclic phenomena for composition operators, Mem. Amer. Math. Soc. 125, 596 (1997), 1-105.

[8] P. S. Bourdon And J. H. Shapiro, Riesz composition operators, Pacific J. Math. 181, 2 (1997), 231-246.

[9] L. Brown, R. G.Douglas, AND P. FILmore, Unitary equivalence modulo the compact operators and extensions of $C^{*}$-algebras, Proc. Conf. Operator Theory, Lecture Notes in Mat., vol. 345, Springer, Berlin, 1973, 58-128.

[10] J. G. Caughran And H. J. Schwartz, Spectra of compact composition operators, Proc. Amer. Math. Soc. 51 (1975), 127-130.

[11] J. A. Cima And A. L. Matheson, Essential norms of composition operators and Aleksandrov measures, Pacific J. Math. 179 (1997), 59-64.

[12] J. A. Cima, J. Thomson, AND W. Wogen, On some properties of composition operators, Indiana U. Math. J. 24, 3 (1974), 215-220.

[13] C. C. Cowen, Composition operators on $H^{2}$, J. Operator Theory 9 (1983), 77-106.

[14] C. C. Cowen And B. D. MaCCluer, Spectra of some composition operators, J. Funct. Anal. 125, 1 (1994), 223-251. 
[15] C. C. Cowen And B. D. MacCluer, Composition Operators on Spaces of Analytic Functions, CRC Press, Boca Raton, New York, London, Tokyo, 1995.

[16] R. G. Douglas, Banach Algebra Techniques in Operator Theory, Academic Press, New York, 1972.

[17] P. L. Duren, Theory of $H^{p}$ Spaces, Academic Press, New York, 1970. Reprinted Dover, 2000.

[18] A. Feintuch, On asymptotic Toeplitz and Hankel operators. The Gohberg anniversary collection, Vol. II (Calgary, AB, 1988), 241-254, Oper. Theory Adv. Appl., 41, Birkhäuser, Basel, 1989.

[19] P. R. Halmos, Measure Theory, Springer-Verlag, New York, 1974.

[20] H. Kamowitz, The spectra of composition operators on $H^{p}$, J. Funct. Anal. 18 (1975), 32-50.

[21] C. KiTAI, Invariant closed sets for linear operators, Ph. D. thesis, University of Toronto, Toronto, Canada, 1982.

[22] G. Koenigs, Recherches sur les intégrales de certaines équations fonctionnelles, Annales Scientifiques de l'École Normale Supérieure(3) 1 (1884), Supplément, 3-41.

[23] B. D. MACCLUER, Components in the space of composition operators, Integral Equations Operator Theory 12, 5 (1989), 725-738.

[24] V. MATACHE, Notes on hypercyclic operators, Acta Sci. Math. (Széged) 58, 1-4 (1993), 401-410.

[25] V. Matache, S-Toeplitz composition operators, Proceedings of the International Conference on Complex and Harmonic Analysis (Thessaloniki, Greece, May 2006), DEStech Publications Inc., Lancaster PA, 2007, 189-205.

[26] V. MATACHE, Composition operators whose symbols have orthogonal powers, Houston J. Math. 37, 3 (2011), 845-857.

[27] E. A. Nordgren, Composition operators, Canad. J. Math. 20 (1968), 442-449.

[28] C. M. PEARCY, Some recent developments in operator theory, Regional Conference Series in Mathematics, No. 36. American Mathematical Society, Providence, RI, 1978.

[29] Сh. Pommerenke, On the iteration of analytic functions in a half-plane I, J. London Math. Soc. (2) 19 (1979), 439-447.

[30] E. SCHRÖDER, Über unendlich viele Algorithmen zur Auflösung der Gleichungen, Math. Ann. 2 (1870), 317-365.

[31] J. H. ShaPIRo, Composition Operators and Classical Function Theory, Springer-Verlag, Berlin, Heidelberg, New York, 1993.

[32] J. H. ShaPIRo, Composition operators and Schroeder's functional equation, Contemp. Math. 213 (1998), 213-228.

[33] J. H. SHAPIRO, What do composition operators know about inner functions?, Monatsh. Math. 130, 1 (2000), 57-70.

[34] J. H. Shapiro And C. Sundberg, Isolation amongst the composition operators, Pacific J. Math. 145, 1 (1990), 117-152.

[35] C. SundBeRG, Measures induced by analytic functions and a problem of Walter Rudin, J. Amer. Math. Soc. 16, 1 (2003), 69-90.

[36] B. Sz.-NAGY AND C. FoIAŞ, Harmonic analysis of operators on Hilbert space, Translated from the French and revised North-Holland Publishing Co., Amsterdam-London; American Elsevier Publishing Co., Inc., New York; Akadémiai Kiadó, Budapest 1970. 